\title{
Sports participation and psychosocial health: a longitudinal observational study in children
}

\author{
Janet Moeijes ${ }^{1,4^{*}}$ D, Jooske T. van Busschbach ${ }^{1,2}$, Ruud J. Bosscher ${ }^{1}$ and Jos W. R. Twisk ${ }^{3}$
}

\begin{abstract}
Background: It is well known that sports participation is positively associated with psychosocial health in children, but details about this association over time are lacking. This study aimed to explore longitudinal associations between several characteristics of sports participation and three aspects of psychosocial health (internalizing problems, externalizing problems and prosocial behaviour) in Dutch children aged 10-12 years.
\end{abstract}

Methods: Data from 695 fourth-grade primary school children were included at baseline; 10-13 months later, 487 children (response rate 70.1\%) were retained. At both time points, children reported on their sports participation (Move and Sports Monitor Questionnaire - Youth Aged 8-12 Years) and psychosocial health (Strength and Difficulties Questionnaire). Longitudinal associations between several characteristics of sports participation and the three aspects of psychosocial health were analysed using linear mixed models, both clustering the repeated measures within children and clustering the children within schools. In addition to crude analyses, analyses were performed adjusting for sex, age, BMl, household composition, SES and frequency of sports participation.

Results: Membership in a sports club, moderate or high frequency of sports participation, performing team sports, performing outdoor sports, performing contact sports and involvement in competition were longitudinally associated with fewer internalizing problems. The longitudinal association of higher frequency of sports participation with fewer internalizing problems was stronger as a child's BMI increased. The association of performing team sports with fewer internalizing problems was only observed for boys. Membership in a sports club and moderate or high frequency of sports participation were also longitudinally associated with better prosocial behaviour. These associations with prosocial behaviour were stronger for girls. None of the characteristics of sports participation examined were longitudinally associated with externalizing problems.

Conclusions: This study shows that from a longitudinal perspective, fewer internalizing problems and better prosocial behaviour were seen in children who were active in sports. Fewer internalizing problems were also associated with the kind of sports participation; for example, with performing outdoor sports. No associations were found for externalizing problems. Future research should preferably take the form of an intervention to investigate whether the observed statistical associations are of a causal nature.

Keywords: Children, Different characteristics of sports participation, Internalizing problems, Externalizing problems, Prosocial behaviour, Longitudinal associations

\footnotetext{
* Correspondence: j.moeijes@windesheim.nl

'Department of Human Movement and Education, Windesheim University of

Applied Sciences, Campus 2-6, Zwolle 8017, CA, The Netherlands

${ }^{4}$ Department of Epidemiology and Biostatistics, VU Medical Center

Amsterdam, Van der Boechorststraat 7, 1081BT Amsterdam, The Netherlands

Full list of author information is available at the end of the article
}

(c) The Author(s). 2018 Open Access This article is distributed under the terms of the Creative Commons Attribution 4.0 International License (http://creativecommons.org/licenses/by/4.0/), which permits unrestricted use, distribution, and reproduction in any medium, provided you give appropriate credit to the original author(s) and the source, provide a link to the Creative Commons license, and indicate if changes were made. The Creative Commons Public Domain Dedication waiver (http://creativecommons.org/publicdomain/zero/1.0/) applies to the data made available in this article, unless otherwise stated. 


\section{Background}

A substantial number of children worldwide suffer from psychosocial health problems [1], which often continue into adulthood [2-4]. The concept of a child's psychosocial health can be defined, on the one hand, as the absence or lower levels of negative traits, such as internalizing problems (i.e., emotional problems and peer problems) and externalizing problems (i.e., conduct disorders and hyperactivity-inattention), and, on the other hand, as the presence, or higher levels, of positive traits such as appropriate social skills [5-7]. Fewer internalizing problems, fewer externalizing problems and better prosocial behaviour reflect better psychosocial health [7]. A child's psychosocial health is not determined in isolation, but is influenced by various social, economic and physical factors [8].

One of these influential factors is sports participation. Studies in adults, adolescents and children show that sports participation has beneficial psychosocial health outcomes [9-12], but details about the relationship between sports participation and psychosocial health are often lacking [13]. Most studies in this field focus primarily on internalizing problems, while the relationship between sports participation and externalizing problems or prosocial behaviour has not often been taken into account. Furthermore, the studies available on the relationship between a child's sports participation and psychosocial health cover only a limited number of characteristics of sports participation. They mainly focus on whether a child participates in sports activities on a regular basis or not [14-16] or the distinction between individual and team sports [15]. Moreover, there are only a few studies with a longitudinal design [16-19]. Compared to a cross-sectional study, a longitudinal study has the advantage of relating the individual development of a certain outcome variable over time to the individual development of, or changes in, other variables [20].

The purpose of this study was to explore whether and how various characteristics of sports participation were longitudinally associated with internalizing problems, externalizing problems and prosocial behaviour in Dutch children aged 10-12 years.

\section{Methods}

\section{Study design and participants}

Data were obtained within a national-representative study, examining sports participation and psychosocial health in fourth and fifth-grade primary school children in the Netherlands. The children in the sample under study were geographically fairly well spread across the Netherlands and came from both rural and urban areas. Furthermore, our sample was comparable with the general Dutch population of primary school children for body mass index (BMI), neighbourhood socioeconomic status (SES) and sports participation (in terms of membership in a sports club).

The study included a cross-sectional component and a longitudinal component. Data were collected from November 2011 to June 2014.

Primary schools were first contacted by telephone and email. Interested schools were sent an email with detailed information and were subsequently approached with additional details and to make an appointment for a visit. If permission was given, the school sent written information about the aim, nature and practical process of the research to the parents and guardians of the children. Written informed consent from a parent or guardian was a precondition for participation in the research.

At the initial meeting, participating children were provided with a booklet containing questionnaires to be completed in the classroom. These completed questionnaires were collected 1 week later. Subsequently, anthropometric data were obtained during school time.

For the longitudinal component of the study, 998 children were invited to participate, with 752 (75.2\%) responding positively. Due to missing data, ultimately 695 fourth-grade primary school children $(69.6 \%$; 334 boys, 361 girls; 29 primary schools) were included in the sample for the first measurement. After a period of 10 to 13 months, 508 children (73.1\%) were retested (now in fifth grade). Due to missing data, 21 retested children (3.0\%) were excluded from the analyses, resulting in a study sample of 487 children (response rate $70.1 \%$; see also Statistical analyses).

The study was conducted in accordance with the guidelines proposed by the World Medical Association Declaration of Helsinki and was approved by the Medical Ethical Committee at VU University Medical Center Amsterdam (Twisk: 12/151). All parents and guardians of children in the sample provided a written informed consent.

\section{Measures \\ Psychosocial health}

Psychosocial health was measured by the self-report version of the Strengths and Difficulties Questionnaire (SDQ), which assesses psychosocial health [21]. Apart from its clinical application, the SDQ has evolved into a screening method in research settings [22, 23] determining strengths and difficulties of children [24]. Due to its brevity and simplicity, the SDQ has become one of the most widely used screening instruments regarding children's psychosocial health $[25,26]$. The inclusion of both strengths and difficulties in the SDQ makes the questionnaire suitable for studies in psychosocially healthy children [27].

The five original subscales of the SDQ measured emotional symptoms, peer problems, conduct problems, 
hyperactivity-inattention and prosocial behaviour, subsequently organized into three broader scales for healthy subjects [7]. Emotional problems and peer problems form the 'internalizing problems scale'. Conduct disorders and hyperactivity-inattention form the 'externalizing problems subscale' and the original prosocial behaviour subscale remained unchanged. The 25 items in the questionnaire are formulated as statements with response categories ranging from 'not true,' 'somewhat true' to 'certainly true'.

We followed the guidelines in the official manual of the SDQ [25] on subscale calculation and missing data. The internal consistency of each of the scales - the internalizing problems subscale, the externalizing problems subscale and the prosocial behaviour subscale - is reflected in Cronbach alphas of $0.66,0.76$ and 0.66 respectively [7]. The test-retest reliability of the Dutch self-report version of the SDQ subscales, expressed in an intraclass correlation coefficient (ICC), is 0.76 or higher, except for the prosocial behaviour subscale, which has an ICC of 0.59 [28].

\section{Sports participation}

The study focused on sports activities in sports clubs, the main environment in which Dutch children participate in sports [29]. A child's participation in sports club activities was measured using two items from the self-report Move and Sports Monitor Questionnaire (MSMQ) - Youth Aged 8-12 Years [30]: membership in a sports club and frequency of training and matches per week. We added a third question about the type of sport(s) in which a child participated, as a means of distinguishing between different kinds of sports.

Sports were defined as team sports when practised by two or more people who cooperate to attain an optimal result and perceive each other as allies, while individual sports were defined as those in which the child is active as a single player and perceives other participants as opponents. In addition, we distinguished between indoor versus outdoor sports and between contact sports such as football and judo and non-contact sports such as volleyball and swimming. The final characteristic of sports participation concerned whether a child was involved in competition or not. The validation of the questions about sports participation was described in Moeijes et al. [31].

\section{Covariates}

The covariates of age (continuous), sex (dichotomous), body mass index (BMI; continuous), household composition (dichotomous) and neighbourhood socioeconomic status (SES; continuous) were used in all analyses. Frequency of sports participation (continuous) was used as a covariate in the analyses of the associations between performing different kinds of sports (i.e. individual versus team sports, indoor versus outdoor sports, contact versus non-contact sports and involvement in competition or not) and psychosocial health. This was done to avoid the risk of finding spurious associations or overlooking important associations.

Parents or guardians reported the child's date of birth and sex. Height and weight were measured by the researchers who visited the schools. Height was measured by the Seca 201 or 203 system (Basel, Switzerland) and weight by the Seca Sensa 804. (Basel, Switzerland) or the Tanita BC 601 digital scale (Tokyo, Japan). BMI was calculated as weight divided by height squared $\left(\mathrm{kg} / \mathrm{m}^{2}\right)$ [32] Household composition was measured as living in a two-parent family or in another type of household, for example a one-parent family [33]. The neighbourhood SES of the child's parents or guardians was based on postcodes and the status score per postcode derived from the Dutch Social and Cultural Planning Office in 2010 [34].

\section{Statistical analyses}

Children who failed to answer one or more questions concerning the sports participation questionnaire MSMQ, BMI, SES or household composition were excluded from the analyses. Children who had missing data concerning the SDQ were excluded according the procedure outlined in the SDQ manual, which meant that for each of the original five subscales it was permitted to have one or two items missing. A greater number of missing data resulted in the exclusion of the child from the analyses.

All data were analysed using IBM SPSS (Version 24, IBM, New York, United States). Data on the outcome variables (internalizing problems, externalizing problems and prosocial behaviour), independent variables (membership in a sports club, frequency of sports participation classified into tertiles, individual versus team sports, indoor versus outdoor sports, contact versus non-contact sports and involvement in competition) and covariates (sex, age, BMI, SES, household composition and frequency of sports participation) for the children who did not participate in the second measurement were compared with the data for the children who participated in both measurements using independent t-tests or Pearson $x^{2}$-tests.

To control for the influence of prior testing, an additional sample of fifth graders was also tested $(N=450$; $52.4 \%$ male, mean age $=12.0$ years, $\mathrm{SD}=0.5 ; 47.6 \%$ female, mean age $=12.0$ years, $\mathrm{SD}=0.5$ ).

The longitudinal relationships between the characteristics of sports participation and psychosocial health (internalizing problems, externalizing problems and prosocial behaviour) were analysed using linear mixed models, taking into account the three-level structure of the data: repeated measures were clustered within 
children and children were clustered within the schools. Before analysis, normality of the distribution of the outcome variables was assessed by visual examination of histograms, which showed that internalizing problems subscale was skewed to the right. This subscale has therefore been log transformed.

In addition to crude analyses, analyses were performed adjusting for sex, age, BMI, household composition, SES and frequency of sports participation. Further analyses were performed to detect effect modifications, with interaction terms for all covariates analysed separately. For all analyses, a two-tailed significance level of $p<0.05$ was considered statistically significant.

\section{Results}

Of the 695 fourth-grade primary school children who filled in the questionnaires in the first test, 487 (70.1\%) also fully completed the questionnaires in the retest (fifth grade) and were included in the study. The 208 children (29.9\%) who were excluded did not participate in the retest because they were not interested, or were excluded due to missing data.

Children who only provided information for the first test measurement differed significantly from the children who were measured twice, with respect to age (11.1 versus 11.0 years, $p=0.002)$ and BMI (18.1 versus $17.6, p=0.02)$ at the moment of the first test. No significant difference was found for sex, SES, household composition, membership in a sports club, frequency of sports participation and the outcome variables.

There was also no influence of prior testing observed, as the scores on the outcome variables did not differ significantly between children who were measured twice and the control group of children, who were only measured in the fifth grade (internalizing problems: $t=1.20$, $p=0.23$; externalizing problems: $t=0.63, \quad p=0.53$; prosocial behaviour: $t=1.05, p=0.29$ ). Demographic characteristics of the entire sample are shown in Table 1.

\section{Internalizing problems}

Table 2 shows the results of the linear mixed model analyses relating characteristics of sports participation and the three indicators of psychosocial behaviour. In both crude and adjusted analyses, membership in a sports club and higher frequency of sports participation were associated with fewer internalizing problems. Furthermore, performing outdoor sports and performing contact sports were also associated with fewer internalizing problems. The same was found for involvement in competition, in comparison with only doing training activities.

BMI and sex were significant effect modifiers. Children with higher BMI showed a stronger longitudinal association between higher frequency of sports participation and fewer internalizing problems compared to children with lower BMI. In addition, a longitudinal association between performing team sports and fewer internalizing problems was found, but only for boys.

\section{Externalizing problems}

Regarding externalizing problems, no significant longitudinal associations with different characteristics of sports participation (Table 3) were found. Moreover, no significant effect modifications were observed.

\section{Prosocial behaviour}

Membership in a sports club and moderate and high frequency of sports participation were longitudinally associated with better prosocial behaviour (Table 4). Additional analyses investigating effect modification demonstrated that the longitudinal relationship for membership and frequency was more pronounced for girls.

\section{Discussion \\ Main findings}

This study investigated the longitudinal relationships between characteristics of sports participation and psychosocial health in children aged 10-12 years. Although the characteristics of sports participation examined appeared to be longitudinally associated with psychosocial health, there were clear differences for the three aspects of psychosocial health. The characteristics of sports participation examined were particularly associated with internalizing problems. There were substantially less associations found between characteristics of sport participation and prosocial behaviour and no associations at all with externalizing problems.

\section{Internalizing problems}

The longitudinal associations observed between all characteristics of sports participation may be explained with the help of the intermediate constructs 'sports self-concept' and 'self-esteem'. A higher sports self-concept is beneficial for a child's self-esteem [19, 35, 36], which is reflected in fewer internalizing problems $[15,37]$.

The longitudinal associations observed between membership in a sports club, moderate or high frequency of sports participation and fewer internalizing problems are in line with the results of other studies [17, 19, 38-40]. An explanation of these longitudinal associations might be that engaging in sports activities enhances a child's sports abilities [11, 41, 42] and consequently stimulates his or her sports self-concept [15, 42, 43].

The association observed between moderate or high frequency of sports participation and fewer internalizing problems was stronger for children with higher BMI. Compared to healthy-weight peers, children with overweight are likely to have a lower self-concept and thereby lower self-esteem, resulting in more internalizing 
Table 1 Demographic characteristics of the sample in the test $(N=695)$ and retest $(N=487)$

\begin{tabular}{|c|c|c|c|c|c|c|c|c|c|}
\hline & & \multicolumn{4}{|c|}{ Fourth grade } & \multicolumn{4}{|c|}{ Fifth grade } \\
\hline & & $\mathrm{N}$ & $\%$ & Mean & SD & $\mathrm{N}$ & $\%$ & Mean & SD \\
\hline \multirow[t]{2}{*}{ Sex } & Boys & 334 & 48.1 & & & 233 & 47.8 & & \\
\hline & Girls & 361 & 51.9 & & & 254 & 52.2 & & \\
\hline Age & & & & 11.0 & 0.5 & & & 11.9 & 0.5 \\
\hline BMI & & & & 17.8 & 2.5 & & & 18.3 & 2.3 \\
\hline SES & & & & 0.25 & 0.91 & & & 0.30 & 0.90 \\
\hline \multirow[t]{2}{*}{ Household composition } & Two parent family & 570 & 82.0 & & & 399 & 81.9 & & \\
\hline & Others & 125 & 18.0 & & & 88 & 18.1 & & \\
\hline \multirow[t]{2}{*}{ Membership sports club } & No & 89 & 12.8 & & & 63 & 12.9 & & \\
\hline & Yes & 606 & 87.2 & & & 424 & 87.1 & & \\
\hline \multirow[t]{5}{*}{ Frequency of sports participation } & & & & 2.92 & 1.44 & & & 2.51 & 1.64 \\
\hline & Nonathletes & 89 & 12.8 & & & 68 & 14.0 & & \\
\hline & Low sports actives & 229 & 32.9 & & & 130 & 26.7 & & \\
\hline & Moderate sports actives & 194 & 27.9 & & & 166 & 34.1 & & \\
\hline & High sports actives & 183 & 26.3 & & & 123 & 25.3 & & \\
\hline \multirow[t]{4}{*}{ Individual versus team sports } & Nonathletes & 89 & 12.8 & & & 68 & 14.0 & & \\
\hline & Individual sports & 161 & 23.2 & & & 108 & 22.2 & & \\
\hline & Team sports & 325 & 46.8 & & & 236 & 48.5 & & \\
\hline & Individual as well as team sports & 120 & 17.3 & & & 75 & 15.4 & & \\
\hline \multirow[t]{4}{*}{ Indoor versus outdoor sports } & Nonathletes & 89 & 12.8 & & & 68 & 14.0 & & \\
\hline & Indoor sports & 207 & 29.8 & & & 130 & 23.7 & & \\
\hline & Outdoor sports & 308 & 44.3 & & & 239 & 49.1 & & \\
\hline & Indoor as well as outdoor sports & 91 & 13.1 & & & 50 & 10.3 & & \\
\hline \multirow[t]{4}{*}{ Contact versus non-contact sports } & Nonathletes & 89 & 12.8 & & & 68 & 14.0 & & \\
\hline & Non-contact sports & 240 & 34.5 & & & 161 & 33.1 & & \\
\hline & Contact sports & 277 & 39.9 & & & 205 & 42.1 & & \\
\hline & Non-contact as well as contact sports & 89 & 12.8 & & & 53 & 10.9 & & \\
\hline \multirow[t]{3}{*}{ Involvement in competition or not } & Nonathletes & 89 & 12.8 & & & 68 & 14.0 & & \\
\hline & Training activities & 139 & 20.0 & & & 86 & 17.7 & & \\
\hline & Competition & 467 & 67.2 & & & 333 & 68.4 & & \\
\hline \multirow[t]{9}{*}{ Psychosocial health } & internalizing problems & & & 3.97 & 2.78 & & & 3.21 & 2.83 \\
\hline & normal & 647 & 93.1 & & & 453 & 93.0 & & \\
\hline & abnormal & 48 & 6.9 & & & 34 & 7.0 & & \\
\hline & externalizing problems & & & 5.53 & 3.07 & & & 5.16 & 3.17 \\
\hline & normal & 572 & 82.3 & & & 403 & 82.8 & & \\
\hline & abnormal & 123 & 17.7 & & & 84 & 17.2 & & \\
\hline & prosocial behaviour & & & 7.90 & 1.62 & & & 8.31 & 1.56 \\
\hline & normal & 642 & 92.4 & & & 450 & 92.4 & & \\
\hline & abnormal & 53 & 7.6 & & & 37 & 7.6 & & \\
\hline
\end{tabular}

problems $[44,45]$. It is probable that their self-concept and self-esteem may only be improved by undertaking sports activities on a very regular basis.

Unlike girls, boys showed a longitudinal association between performing team sports and fewer internalizing problems. An explanation for this sex effect might be that success in sports activities is of greater importance for self-esteem in boys than in girls [36, 46]. As a consequence, boys might have a greater urge to perform well at sports in cooperation with their peers. Their joint 
Table 2 Longitudinal associations of examined characteristics of sports participation with internalizing problems $(N=487)$

\begin{tabular}{|c|c|c|c|c|c|c|c|}
\hline & & Linear mix & models & & & & \\
\hline & & Raw analys & & & Adjusted ar & nalyses ${ }^{a}$ & \\
\hline & & $\overline{\mathrm{B}^{\mathrm{b}}}$ & $P$ & $\mathrm{Cl}$ & $\mathrm{B}^{\mathrm{b}}$ & $p$ & $\mathrm{Cl}$ \\
\hline Sports participation & Nonathletes & Reference & & & Reference & & \\
\hline & Membership sports club & -0.25 & $<0.001^{* * *}$ & -0.37 to -0.13 & -0.25 & $<0.001^{* * *}$ & -0.37 to -0.13 \\
\hline Frequency of sports & High sports actives & Reference & & & Reference & & \\
\hline & Moderate sports actives & 0.02 & 0.71 & $-0.09-0.13$ & 0.04 & 0.42 & $-0.06-0.15$ \\
\hline & Low sports actives & 0.17 & $0.004^{* *}$ & $0.05-0.28$ & 0.13 & $0.02^{*}$ & $0.02-0.24$ \\
\hline & Nonathletes & 0.33 & $<0.001^{* * *}$ & $0.18-0.47$ & 0.32 & $<0.001^{* * *}$ & $0.17-0.47$ \\
\hline Individual versus team sports & Individual sports & Reference & & & Reference & & \\
\hline & Team sports & -0.10 & 0.09 & $-0.21-0.02$ & -0.08 & 0.20 & $-0.20-0.04$ \\
\hline & Individual as well as team sports & -0.01 & 0.87 & $-0.15-0.13$ & 0.02 & 0.84 & $-0.14-0.17$ \\
\hline & Nonathletes & 0.19 & $0.01^{* *}$ & $0.05-0.34$ & 0.14 & 0.10 & $-0.02-0.30$ \\
\hline Indoor versus outdoor sports & Indoor sports & Reference & & & Reference & & \\
\hline & Outdoor sports & -0.28 & $<0.001^{* * *}$ & -0.38 to -0.17 & -0.22 & $<0.001^{* * *}$ & -0.34 to -0.11 \\
\hline & Indoor as well as outdoor sports & -0.10 & 0.20 & $-0.25-0.05$ & -0.08 & 0.30 & $-0.24-0.08$ \\
\hline & Nonathletes & 0.10 & 0.16 & $-0.04-0.24$ & 0.10 & 0.23 & $-0.06-0.25$ \\
\hline Contact versus & Non-contact sports & Reference & & & Reference & & \\
\hline & Contact sports & -0.19 & $0.001^{* * *}$ & -0.30 to -0.09 & -0.12 & $0.05^{*}$ & $-0.25-0.00$ \\
\hline & Non-Contact as well as contact sports & -0.07 & 0.34 & $-0.22-0.08$ & -0.05 & 0.53 & $-0.20-0.10$ \\
\hline & Nonathletes & 0.16 & $0.02^{*}$ & $0.02-0.29$ & 0.19 & $0.01^{* *}$ & $0.05-0.32$ \\
\hline Involvement in & Competition & Reference & & & Reference & & \\
\hline on or not & Training activities & 0.16 & $0.003^{* *}$ & $0.05-0.27$ & 0.09 & 0.15 & $-0.03-0.22$ \\
\hline & Nonathletes & 0.30 & $<0.001^{* * *}$ & $0.17-0.43$ & 0.29 & $0.01^{* *}$ & $0.08-0.43$ \\
\hline
\end{tabular}

${ }^{a}$ Adjusted for sex, age, BMI, neighbourhood SES and household composition. For the variables individual versus team sports, indoor versus outdoor sports, contact versus non-contact sports, and involvement in competition, the analyses were also adjusted for frequency of sports participation

bunstandardized regression coefficient

Italic values represent statistically significant results; ${ }^{*} p \leq .05 ;{ }^{* *} p \leq .01 ;{ }^{* * *} p \leq .001$

efforts to achieve good sports results could lead to a stronger sense of belonging during sports activities [47], resulting in higher self-esteem.

One explanation for the longitudinal association observed between performing contact sports and fewer internalizing problems might be that contact sports take place in a context in which children explore the social borders of permitted physical contact. This might reduce the uncertainty of the child about how to behave towards peers [48] and thereby promote his or her self-esteem [49].

A recent study on the effects of participating in competition in adolescence [50] found the same positive effect on mental health as our study of children. Despite the fact that children do not always win such competitive sports matches, they do offer the opportunity to experience success and might therefore improve self-esteem [51].

Our finding that performing outdoor sports was longitudinally associated with fewer internalizing problems is also in accordance with some previous studies [52, 53].
These studies reported that being active outdoors is additionally beneficial, as the open air itself has a positive influence with respect to a reduction in depressive feelings, which constitute an essential element of internalizing problems.

\section{Externalizing problems}

In line with the results of other recent studies $[17,18$, 54, 55], we found no longitudinal association between characteristics of sports participation and externalizing problems. This might be explained with the help of the intermediate concept of 'effortful control'. Externalizing problems can be considered a consequence of a lack of effortful control, which means an insufficient 'ability to willfully or voluntarily inhibit, activate, or change (modulate) attention and behavior, as well as executive functioning tasks of planning, detecting errors, and integrating information relevant to selecting behavior' [56]. Effortful control is a trait of an individual's temperament, which mainly evolves between the ages of 2 and 7 [57]. The children in our sample, who were aged 
Table 3 Longitudinal associations of examined characteristics of sports participation with externalizing problems $(N=487)$

\begin{tabular}{|c|c|c|c|c|c|c|c|}
\hline & & Linear mix & Ddels & & & & \\
\hline & & Raw analys & & & Adjusted ar & lyses $^{a}$ & \\
\hline & & $\overline{B^{b}}$ & $P$ & $\mathrm{Cl}$ & $\overline{B^{b}}$ & $p$ & $\mathrm{Cl}$ \\
\hline Sports participation & Nonathletes & Reference & & & Reference & & \\
\hline & Membership sports club & -0.22 & 0.44 & $-0.77-0.33$ & -0.30 & 0.28 & $-0.86-0.25$ \\
\hline Frequency of sports & High sports actives & Reference & & & Reference & & \\
\hline & Moderate sports actives & -0.10 & 0.67 & $-0.57-0.37$ & -0.09 & 0.72 & $-0.56-0.39$ \\
\hline & Low sports actives & -0.04 & 0.88 & $-0.54-0.47$ & -0.02 & 0.94 & $-0.53-0.49$ \\
\hline & Nonathletes & 0.17 & 0.62 & $-0.49-0.82$ & 0.27 & 0.43 & $-0.39-0.93$ \\
\hline Individual versus team sports & Individual sports & Reference & & & Reference & & \\
\hline & Team sports & 0.03 & 0.91 & $-0.50-0.56$ & -0.04 & 0.87 & $-0.59-0.50$ \\
\hline & Individual as well as team sports & 0.10 & 0.75 & $-0.53-0.74$ & -0.10 & 0.77 & $-0.79-0.59$ \\
\hline & Nonathletes & 0.25 & 0.45 & $-0.39-0.89$ & 0.48 & 0.20 & $-0.25-1.21$ \\
\hline Indoor versus outdoor sports & Indoor sports & Reference & & & Reference & & \\
\hline & Outdoor sports & -0.21 & 0.42 & $0.73-0.30$ & -0.34 & 0.23 & $-0.88-0.21$ \\
\hline & Indoor as well as outdoor sports & 0.19 & 0.59 & $-0.50-0.88$ & 0.02 & 0.96 & $-0.72-0.75$ \\
\hline & Nonathletes & 0.14 & 0.66 & $-0.48-0.76$ & 0.35 & 0.33 & $-0.35-1.05$ \\
\hline Contact versus & Non-contact sports & Reference & & & Reference & & \\
\hline & Contact sports & 0.16 & 0.53 & $-0.34-0.69$ & 0.11 & 0.70 & $-0.46-0.69$ \\
\hline & Non-Contact as well as contact sports & 0.47 & 0.17 & $-0.21-1.15$ & 0.31 & 0.42 & $-0.46-1.08$ \\
\hline & Nonathletes & 0.33 & 0.29 & $-0.27-0.93$ & 0.48 & 0.17 & $-0.21-1.18$ \\
\hline Involvement in & Competition & Reference & & & Reference & & \\
\hline ion or not & Training activities & 0.21 & 0.41 & $-0.29-0.70$ & 0.47 & 0.10 & $-0.10-1.04$ \\
\hline & Nonathletes & 0.29 & 0.32 & $-0.29-0.87$ & 0.85 & $0.04^{*}$ & $0.06-1.64$ \\
\hline
\end{tabular}

${ }^{a}$ Adjusted for sex, age, BMI, neighbourhood SES and household composition. For the variables individual versus team sports, indoor versus outdoor sports, contact versus non-contact sports and involvement in competition, the analyses were also adjusted for frequency of sports participation

bunstandardized regression coefficient

Italic value represents statistically significant result; ${ }^{*} p<.05$

between 10 and 12 years, had probably already achieved such stability in their effortful control, such that this characteristic of their temperament was little influenced by participating in sports activities.

\section{Prosocial behaviour}

Our finding that membership in a sports club and frequency of sports participation were longitudinally associated with better prosocial behaviour confirms what has been described in other studies $[18,54,58]$. The disciplinary effect of engagement in sports activities on the behaviour of children $[18,41]$ probably also applies more specifically to their prosocial behaviour [59, 60]. The repetition of rules, i.e. bringing specific rules of conduct to the attention of children regularly and giving them sufficient opportunity to put them into practice, is conducive to developing and sustaining adequate prosocial behaviour.

The more pronounced longitudinal associations for girls could be due to a difference between the sexes in how aggression and empathy are expressed during sports. Girls behave less aggressively than boys during sports activities because of both complex social and cultural expectations and the physical characteristics of boys and girls [61, 62]. Stanger et al. [61] found that the sports attitudes of men were more aggressive than those of women. Women have an attitude to sports which is characterized more by empathy, which tends to prevent them from acting aggressively towards other people [63] and is therefore conducive to the development of prosocial behaviour.

\section{Strengths and limitations}

This study presents essential outcomes concerning longitudinal relationships between sports participation and psychosocial health in children aged 10-12 years. The external validity of the study outcomes was improved by gathering longitudinal data using a large-scale survey of children from a considerable number of regular primary schools throughout the Netherlands, covering a wide variety of household composition and socioeconomic status. 
Table 4 Longitudinal associations of examined characteristics of sports participation with prosocial behaviour $(N=487)$

\begin{tabular}{|c|c|c|c|c|c|c|c|}
\hline & & \multicolumn{6}{|c|}{ Linear mix models } \\
\hline & & \multicolumn{3}{|c|}{ Raw analyses } & \multicolumn{3}{|c|}{ Adjusted analyses $^{a}$} \\
\hline & & $\mathrm{B}^{\mathrm{b}}$ & $P$ & $\mathrm{Cl}$ & $\mathrm{B}^{\mathrm{b}}$ & $p$ & $\mathrm{Cl}$ \\
\hline \multirow[t]{2}{*}{ Sports participation } & Nonathletes & Reference & & & Reference & & \\
\hline & Membership sports club & 0.30 & $0.05^{*}$ & $0.00-0.60$ & 0.40 & $0.01^{* *}$ & $0.10-0.69$ \\
\hline \multirow{4}{*}{$\begin{array}{l}\text { Frequency of sports } \\
\text { participation }\end{array}$} & High sports actives & Reference & & & Reference & & \\
\hline & Moderate sports actives & -0.02 & 0.89 & $-0.28-0.24$ & 0.01 & 0.93 & $-0.25-0.27$ \\
\hline & Low sports actives & -0.16 & 0.25 & $-0.44-0.11$ & -0.24 & 0.08 & $-0.51-0.03$ \\
\hline & Nonathletes & -0.37 & $0.04^{*}$ & -0.73 to -0.02 & -0.51 & $0.004^{* *}$ & -0.86 to -0.16 \\
\hline \multirow[t]{4}{*}{ Individual versus team sports } & Individual sports & Reference & & & Reference & & \\
\hline & Team sports & -0.13 & 0.34 & $-0.41-0.14$ & -0.06 & 0.69 & $-0.34-0.22$ \\
\hline & Individual as well as team sports & -0.06 & 0.71 & $-0.40-0.27$ & -0.16 & 0.40 & $-0.52-0.21$ \\
\hline & Nonathletes & -0.38 & $0.03^{*}$ & -0.72 to -0.03 & -0.27 & 0.18 & $-0.66-0.12$ \\
\hline \multirow[t]{4}{*}{ Indoor versus outdoor sports } & Indoor sports & Reference & & & Reference & & \\
\hline & Outdoor sports & 0.08 & 0.57 & $-0.19-0.34$ & 0.25 & 0.08 & $-0.02-0.53$ \\
\hline & Indoor as well as outdoor sports & 0.09 & 0.62 & $-0.27-0.46$ & 0.03 & 0.89 & $-0.35-0.41$ \\
\hline & Nonathletes & -0.25 & 0.15 & $-0.58-0.09$ & -0.15 & 0.44 & $-0.53-0.23$ \\
\hline \multirow{4}{*}{$\begin{array}{l}\text { Contact versus } \\
\text { non-contact sports }\end{array}$} & Non-contact sports & Reference & & & Reference & & \\
\hline & Contact sports & -0.16 & 0.22 & $-0.42-0.10$ & 0.08 & 0.60 & $-0.12-0.37$ \\
\hline & Non-Contact as well as contact sports & -0.14 & 0.45 & $-0.50-0.22$ & -0.13 & 0.52 & $-0.53-0.27$ \\
\hline & Nonathletes & -0.38 & $0.02^{*}$ & -0.71 to -0.05 & -0.20 & 0.29 & $-0.60-0.17$ \\
\hline \multirow{3}{*}{$\begin{array}{l}\text { Involvement in } \\
\text { competition or not }\end{array}$} & Competition & Reference & & & Reference & & \\
\hline & Training activities & -0.10 & 0.45 & $-0.37-0.16$ & -0.17 & 0.26 & $-0.49-0.04$ \\
\hline & Nonathletes & -0.33 & $0.04^{*}$ & -0.64 to -0.02 & -0.38 & 0.08 & $-0.48-0.13$ \\
\hline
\end{tabular}

${ }^{a}$ Adjusted for sex, age, BMI, neighbourhood SES and household composition. For the variables individual versus team sports, indoor versus outdoor sports, contact versus non-contact sports and involvement in competition, the analyses were also adjusted for frequency of sports participation

bunstandardized regression coefficient

Italic values represent statistically significant results; ${ }^{*} p \leq .05 ;{ }^{* *} p \leq .01$

Unlike most other studies in this field, our study did not focus on one or more specific psychosocial disorder such as depression or behavioural problems, but on three general aspects of psychosocial health, namely the absence of internalizing and externalizing problems and the presence of prosocial behaviour.

A further strength of our study is that a substantial number of characteristics of sports participation were taken into account. Most studies on the relationship between sports participation and psychosocial health only focus on a limited number of characteristics of sports participation.

The final strength pertains to the advantage of longitudinal analyses compared with cross-sectional analyses. In the case of longitudinal analyses, the estimated relationships reflect both the within-subject relationships and the between-subject relationships. Furthermore, the observations within a child at different time points are highly correlated. This correlation is overlooked in cross-sectional analyses.

There are, however, also some limitations. Although the time spent in sports participation is probably more strongly associated with psychosocial health than membership in a sports club and frequency of sports participation [64], we did not take the duration of sports participation into account in our analyses. Using self-reported information from the children, rather than objectively measured data about physical activity, it was not possible to assess the time spent in sports participation in a valid way.

Another limitation is that the longitudinal observational design only provided the opportunity to determine statistical associations. Because no intervention was performed, no causal relationships could be established. Furthermore, the follow-up period for the longitudinal study was relatively short (i.e. 10-13 months) and the study only included children within the age range of 10 to 12 years. The outcomes cannot be generalized to other age groups.

Finally, only two confounders used in the statistical analyses related to a child's social, cultural and economic circumstances, namely socioeconomic status and household composition. Because contextual factors might have an impact on the relationship between sports participation 
and psychosocial health, the study would have been strengthened by paying more attention to such factors.

\section{Future research}

In this study, the numerous associations between characteristics of sports participation and internalizing problems were explained on the basis of the assumption that a higher sports self-concept is beneficial for a child's self-esteem, which is reflected in fewer internalizing problems. Although there is some research available that supports this explanation, future research could explicitly pay attention to children's sports self-concept and their self-esteem as potential explanatory mechanisms. Furthermore, future research should preferably take place in the form of an intervention in order to investigate whether the statistical associations found in our research are of a causal nature. Finally, future research should pay more attention to children's social, cultural and economic circumstances. In this respect, the cultural and ethnic background of the children might also be considered.

\section{Conclusions}

This study found that, from a longitudinal perspective, children who were active in sports exhibited fewer internalizing problems and better prosocial behaviour. Fewer internalizing problems were also associated with the kind of sports participation, for example with performing outdoor sports. No associations were found for externalizing problems. Future research should preferably take place in the form of an intervention to investigate whether the observed statistical associations are of a causal nature.

\section{Abbreviations}

BMI: Body mass index; SDQ: Strengths and Difficulties Questionnaire: SES: Socioeconomic status

\section{Acknowledgements}

We gratefully thank the children and schools for their participation in the study.

\section{Availability of data and materials}

The datasets used and/or analysed during the current study are available from the corresponding author on reasonable request.

\section{Authors' contributions}

The study was designed by JM, RB and JT. Analysis was performed by JM, JVB and JT. The first draft of the paper was written by JM, and all authors provided critical input and revisions. JM finalised the manuscript which was subsequently approved by all authors. All authors approved the final manuscript as submitted.

\section{Ethics approval and consent to participate}

All procedures performed in studies involving human participants were in accordance with the ethical standards of the institutional and/or national research committee and with the 1964 Helsinki declaration and its later amendments or comparable ethical standards. Ethical approval was obtained from the Medical Ethical Committee of VU University Medical Center Amsterdam (Twisk: 12/151)

All parents and guardians of children in the sample provided a written informed consent.
Consent for publication

Participants consented to have all anonymised data available for publication.

Competing interests

The authors declare that they have no competing interests.

\section{Publisher's Note}

Springer Nature remains neutral with regard to jurisdictional claims in published maps and institutional affiliations.

\section{Author details}

${ }^{1}$ Department of Human Movement and Education, Windesheim University of Applied Sciences, Campus 2-6, Zwolle 8017, CA, The Netherlands. ${ }^{2}$ University Medical Center Groningen, University Center for Psychiatry, PO Box 30001, 9700, RB, Groningen, The Netherlands. ${ }^{3}$ Department of Public and Occupational Health, Amsterdam Public Health research institute (VUmc), Van der Boechorststraat 7, Amsterdam 1081, BT, The Netherlands.

${ }^{4}$ Department of Epidemiology and Biostatistics, VU Medical Center Amsterdam, Van der Boechorststraat 7, 1081BT Amsterdam, The Netherlands.

Received: 26 April 2018 Accepted: 29 May 2018

Published online: 07 June 2018

References

1. World Health Organization. Social determinants of mental health. Geneva: World Health Organization; 2014.

2. Kieling C, Baker-Henningham H, Belfer M, Conti G, Ertem I, Omigbodun O, et al. Child and adolescent mental health worldwide: evidence for action. Lancet. 2011;378(9801):1515-25.

3. Jewett R, Sabiston CM, Brunet J, O'Loughlin EK, Scarapicchia T, O'Loughlin J. School sport participation during adolescence and mental health in early adulthood. J Adolesc Health. 2014;55(5):640-4

4. Marmot M, Allen J, Bell R, Bloomer E, Goldblatt P. WHO European review of social determinants of health and the health divide. Lancet. 2012;380(9846): 1011-29.

5. Clarke AT. Coping with interpersonal stress and psychosocial health among children and adolescents: a meta-analysis. J Youth Adolescence. 2006:35(1):10-23.

6. Hinkley T, Teychenne M, Downing KL, Ball K, Salmon J, Hesketh KD. Early childhood physical activity, sedentary behaviors and psychosocial wellbeing: a systematic review. Prev Med. 2014;62:182-92.

7. Goodman A, Lamping DL, Ploubidis GB. When to use broader internalising and externalising subscales instead of the hypothesised five subscales on the Strengths and Difficulties Questionnaire (SDQ): data from British parents, teachers and children. J Abnorm Child Psych. 2010;38(8):1179-91. https:// doi.org/10.1007/s10802-010-9434-X.

8. Allen J, Balfour R, Bell R, Marmot M. Social determinants of mental health Int Rev Psychiatr. 2014;26(4):392-407.

9. Ahn S, Fedewa AL. A meta-analysis of the relationship between children's physical activity and mental health. J Pediatr Psychol. 2011;36(4):385-97. https://doi.org/10.1093/jpepsy/jsq107.

10. Biddle SJ, Asare M. Physical activity and mental health in children and adolescents: a review of reviews. Brit J Sport Med. 2011:45(11):886-95. https://doi.org/10.1136/bjsports-2011-090185.

11. Eime RM, Young JA, Harvey JT, Charity MJ, Payne WR. A systematic review of the psychological and social benefits of participation in sport for children and adolescents: informing development of a conceptual model of health through sport. Int J Behav Nutr Phy. 2013;10(1):98-119. https://doi.org/10. 1186/1479-5868-10-98.

12. Eime RM, Young JA, Harvey JT, Charity MJ, Payne WR. A systematic review of the psychological and social benefits of participation in sport for adults: informing development of a conceptual model of health through sport. Int J Behav Nutr Phy. 2013;10(1):135-48.

13. Lubans D, Richards J, Hillman C, Faulkner G, Beauchamp M, Nilsson M, et al. Physical activity for cognitive and mental health in youth: a systematic review of mechanisms. Pediatrics. 2016;138:e20161642.

14. McKercher C, Schmidt MD, Sanderson K, Dwyer T, Venn AJ. Physical activity and depressed mood in primary and secondary school-children. Ment Health Phys Act. 2012;5(1):50-6. https://doi.org/10.1016/j.mhpa.2012.03.004.

15. Slutzky CB, Simpkins SD. The link between children's sport participation and self-esteem: exploring the mediating role of sport self-concept. Psychol Sport Exerc. 2009;10(3):381-9. https://doi.org/10.1016/j.psychsport.2008.09.006. 
16. Zarrett N, Fay K, Li Y, Carrano J, Phelps E, Lerner RM. More than child's play: variable-and pattern-centered approaches for examining effects of sports participation on youth development. Dev Psychol. 2009;45(2):368. https:// doi.org/10.1037/a0014577.

17. Vella SA, Cliff DP, Magee CA, Okely AD. Associations between sports participation and psychological difficulties during childhood: a two-year follow up. J Sci Med Sport. 2014;18(3):304-9. https://doi.org/10.1016/j.jsams.2014.05.006.

18. Denault A-S, Déry M. Participation in organized activities and conduct problems in elementary school the mediating effect of social skills. J Emot Behav Disord. 2014;23(3):167-79. https://doi.org/10.1177/1063426614543950.

19. Findlay LC, Coplan RJ. Come out and play: shyness in childhood and the benefits of organized sports participation. Can J Behav Sc. 2008;40(3):15361. https://doi.org/10.1037/0008-400X.40.3.153.

20. Twisk JW. Applied longitudinal data analysis for epidemiology. A practical guide. Cambridge: Cambridge University Press; 2013.

21. Goodman R. Psychometric properties of the strengths and difficulties questionnaire. J Am Acad Child Psy. 2001:40(11):1337-45.

22. Rothenberger A, Becker A, Erhart M, Wille N, Ravens-Sieberer U, Group BS Psychometric properties of the parent strengths and difficulties questionnaire in the general population of German children and adolescents: results of the BELLA study. Eur Child Adoles Psy. 2008;17(1):99-105.

23. Borg A-M, Salmelin R, Kaukonen P, Joukamaa M, Tamminen T. Feasibility of the Strengths and Difficulties Questionnaire in assessing children's mental health in primary care: Finnish parents', teachers' and public health nurses' experiences with the SDQ. J Child Adoles Ment Health. 2014;26(3):229-38

24. Cooper M. School-based counselling in UK secondary schools: a review and critical evaluation. Glasgow: University of Strathclyde; 2013.

25. Youth in Mind Manual SDQ. 2012. http://www.sdqinfo.com/. Accessed 15 May 2012.

26. Vostanis P. Strengths and Difficulties Questionnaire: research and clinical applications. Curr Opin Psychiatr. 2006;19(4):367-72.

27. Van Roy B, Veenstra M, Clench-Aas J. Construct validity of the five-factor Strengths and Difficulties Questionnaire (SDQ) in pre-, early, and late adolescence. J Child Psychol Psyc. 2008;49(12):1304-12.

28. Muris P, Meesters C, Van den Berg F. The Strengths and Difficulties Questionnaire (SDQ). Eur Child Adoles Psy. 2003;12(1):1-8. https://doi.org/10. 1007/s00787-003-0298-2.

29. Collard D, Factsheet PI. 2015/16 Sportdeelname [Factsheet 2015/16 Sports participation]. Utrecht: Mulier Instituut; 2015.

30. Ooijendijk W, Wendel-Vos W, De Vries S. Consensus Vragenlijsten Sport en Bewegen [Consensus Questionnaires Sports and Movement]. Leiden: TNO Kwaliteit van Leven; 2007. Report No.: KvL//B\&G 2007.089

31. Moeijes J, Van Busschbach JT, Fortuin B, Bosscher RJ, Twisk JW. Sports Participation and Psychosocial health in elementary school children: a crosssectional study. Health Behav Policy Rev 2017;4(6):582-592. https://doi.org/ 10.14485/HBPR.4.6.8

32. Cole TJ, Bellizzi MC, Flegal KM, Dietz WH. Establishing a standard definition for child overweight and obesity worldwide: international survey. BMJ (Clinical research ed). 2000;320:1240-3. https://doi.org/10.1136/bmj.320.7244.1240

33. Lee D, McLanahan S. Family structure transitions and child development: instability, selection, and population heterogeneity. Am Sociol Rev. 2015; 80(4):738-63. https://doi.org/10.1177/0003122415592129.

34. Knol F, Boelhouwer J, Ross JA. Statusontwikkeling van wijken in Nederland 1998-2010 [Status development of neighborhoods in the Netherland 19982010]. Sociaal en Cultureel Planbureau. 2010. Retrieved from: http://www. scp.nl/Publicaties/Alle_publicaties/Publicaties_2012/Statusontwikkeling_van_ wijken_in_Nederland_1998_2010. Accessed 15 Jan 2013.

35. Lee EJ, Stone SI. Co-occurring internalizing and externalizing behavioral problems: the mediating effect of negative self-concept. J Youth Adolesc. 2012;41(6):717-31. https://doi.org/10.1007/s10964-011-9700-4.

36. Bowker $\mathrm{A}$. The relationship between sports participation and self-esteem during early adolescence. Can J Behav Sci. 2006;38(3):214-29. https://doi. org/10.1037/cjbs2006009.

37. Bowker A, Gadbois S, Cornock B. Sports participation and self-esteem: variations as a function of gender and gender role orientation. Sex Roles. 2003;49(1-2):47-9. doi:0360-0025/03/0700-0047/0

38. Schumacher Dimech A, Seiler R. Extra-curricular sport participation: a potential buffer against social anxiety symptoms in primary school children. J Sport Exerc Psychol. 2011;12(4):347-54. https://doi.org/10.1016/j. psychsport.2011.03.007.
39. Gulbin JP, Croser MJ, Morley EJ, Weissensteiner Jr. An integrated framework for the optimisation of sport and athlete development: a practitioner approach. J Sports Sci. 2013;31(12):1319-31.

40. Tucker $\mathrm{R}$, Collins M. What makes champions? A review of the relative contribution of genes and training to sporting success. Br J Sports Med. 2012:46(8):555-61.

41. Donaldson SJ, Ronan KR. The effects of sports participation on young adolescents' emotional well-being. Adolescence. 2006;41(162):369-89.

42. García PLR, Marcos LT, Guillamón AR, García-Cantó E, Pérez-Soto JJ, Casas $A G$, et al. Physical fitness level and its relationship with self-concept in school children. Psychology. 2014;5(18):2009-17. https://doi.org/10.4236/ psych.2014.518204.

43. Babic MJ, Morgan PJ, Plotnikoff RC, Lonsdale C, White RL, Lubans DR. Physical activity and physical self-concept in youth: systematic review and meta-analysis. Sports Med. 2014:44(11):1589-601.

44. Dietz WH, Robinson TN. Overweight children and adolescents. N Engl J Med. 2005:352(20):2100-9.

45. Fagg J, Chadwick P, Cole T, Cummins S, Goldstein H, Lewis $H$, et al. From trial to population: a study of a family-based community intervention for childhood overweight implemented at scale. Int J Obes. 2014;38(10):1343.

46. Daley AJ. Extra-curricular physical activities and physical self-perceptions in British 14-15-year-old male and female adolescents. Eur Phys Educ Rev. 2002;8(1):37-49. https://doi.org/10.1177/1356336X020081003.

47. Miller BW, Roberts GC, Ommundsen Y. Effect of motivational climate on sportspersonship among competitive youth male and female football players. Scand J Med Sci Spor. 2004;14(3):193-202.

48. Haudenhuyse RP, Theeboom M, Coalter F. The potential of sports-based social interventions for vulnerable youth: implications for sport coaches and youth workers. J Youth Stud. 2012;15(4):437-54.

49. Batista M, Cubo DS, Honório S, Martins J. The practice of physical activity related to self-esteem and academical performance in students of basic education. J Hum Sport Exerc. 2016;11(2):297-310.

50. Breistøl S, Clench-Aas J, Van Roy B, Raanaas RK. Association between participating in noncompetitive or competitive sports and mental health among adolescents-a Norwegian population-based cross-sectional study. Scand J Child Adolesc Psychiatr Psychol. 2017;5(1):28-38.

51. Evans MB, Allan V, Erickson K, Martin LJ, Budziszewski R, Côté J. Are all sport activities equal? A systematic review of how youth psychosocial experiences vary across differing sport activities. Br J Sport Med. 2016; https://doi.org/10. 1136/bjsports-2016-096725

52. Thompson Coon J, Boddy K, Stein K, Whear R, Barton J, Depledge MH. Does participating in physical activity in outdoor natural environments have a greater effect on physical and mental wellbeing than physical activity indoors? A systematic review. Environ Sci Technol. 2011;45(5):1761-72. https://doi.org/10.1021/es102947t.

53. Barton J, Pretty J. What is the best dose of nature and green exercise for improving mental health? A multi-study analysis. Environ Sci Technol. 2010; 44(10):3947-55. https://doi.org/10.1021/es903183r.

54. Howie LD, Lukacs SL, Pastor PN, Reuben CA, Mendola P. Participation in activities outside of school hours in relation to problem behavior and social skills in middle childhood. J School Health. 2010;80(3):119-25. https://doi. org/10.1111/j.1746-1561.2009.00475.x.

55. Sagatun A, Søgaard AJ, Bjertness E, Selmer R, Heyerdahl S. The association between weekly hours of physical activity and mental health: a three-year follow-up study of 15-16-year-old students in the city of Oslo, Norway. BMC Public Health. 2007;7(1):155-64. https://doi.org/10.1186/1471-2458-7-155.

56. Eisenberg N, Smith CL, Effortful Control STL. Relations with emotion regulation, adjustment, and socialization in childhood. In: Vohs $\mathrm{K}$, Baumeister R, editors. Handbook of self-regulation: research, theory, and applications. New York: The Guilford Press; 2004. p. 263-83.

57. Schermerhorn AC, Bates JE, Goodnight JA, Lansford JE, Dodge KA, Pettit GS. Temperament moderates associations between exposure to stress and children's externalizing problems. Child Dev. 2013;84(5):1579-93. https://doi. org/10.1111/cdev.12076.

58. Fletcher AC, Nickerson P, Wright KL. Structured leisure activities in middle childhood: links to well-being. J Community Psychol. 2003;31(6):641-59. https://doi.org/10.1002/jcop.10075.

59. Rutten EA, Stams GJJ, Biesta GJ, Schuengel C, Dirks E, Hoeksma JB. The contribution of organized youth sport to antisocial and prosocial behavior in adolescent athletes. J Youth Adolescence. 2007;36(3):255-64. 
60. Byrd B, Martin JJ. The relationships among youth running programs multidimensional climates and social responsibility and belonging. J Clin Sport Psychol. 2016;10(1):19-31.

61. Stanger N, Kavussanu M, Ring C. Gender moderates the relationship between empathy and aggressiveness in sport: the mediating role of anger. J Appl Sport Psychol. 2017;29(1):44-58.

62. Coulomb-Cabagno G, Rascle O. Team sports players' observed aggresion as a function of gender, competitive level, and sport type. J Appl Soc Psychol. 2006;36(8):1980-2000.

63. Kavussanu M, Stanger N, Boardley ID. The Prosocial and antisocial behaviour in sport scale: further evidence for construct validity and reliability. I Sport Sci. 2013;31(11):1208-21.

64. Poitras VJ, Gray CE, Borghese MM, Carson V, Chaput J-P, Janssen I, et al. Systematic review of the relationships between objectively measured physical activity and health indicators in school-aged children and youth. Appl Physiol Nutr Metab. 2016;41(6):S197-239.

Ready to submit your research? Choose BMC and benefit from:

- fast, convenient online submission

- thorough peer review by experienced researchers in your field

- rapid publication on acceptance

- support for research data, including large and complex data types

- gold Open Access which fosters wider collaboration and increased citations

- maximum visibility for your research: over $100 \mathrm{M}$ website views per year

At BMC, research is always in progress.

Learn more biomedcentral.com/submissions 